\title{
Deep Peroneal Nerve
}

National Cancer Institute

\section{Source}

National Cancer Institute. Deep Peroneal Nerve. NCI Thesaurus. Code C92602.

A branch of the common peroneal nerve. It innervates the ankle and toes. 